\title{
Diurnal vertical migration of the Atka mackerel Pleurogrammus monopterygius as shown by archival tags
}

\author{
Daniel G. Nichol* ${ }^{*}$ David A. Somerton \\ National Marine Fisheries Service, Alaska Fisheries Science Center, Resource Assessment and \\ Conservation Engineering Division, 7600 Sand Point Way NE, Seattle, Washington 98115-0070, USA
}

\begin{abstract}
Atka mackerel Pleurogrammus monopterygius were captured and tagged with depth and temperature recording devices (archival tags) on 23 July 2000 in Seguam Pass, Aleutian Islands, Alaska. Nine of the 117 tagged fish were recovered in Seguam Pass during September 2000. Fish were tagged externally just below the dorsal fin. Atka mackerel displayed strong diel behavior, with vertical movements away from the bottom occurring almost exclusively during daylight hours and little to no movement at night. Vertical movements occurred when light levels at $150 \mathrm{~m}$ were greater than $7.31 \times 10^{-5} \mu \mathrm{mol}$ photons $\mathrm{m}^{-2} \mathrm{~s}^{-1}$, or approximately between 08:00 and 23:00 h Alaska Daylight Time (ADT; GMT - 8) during August. Daytime vertical movements were correlated with light intensity, time of day and current velocity. The occurrence of vertical movements tended to increase with increasing light during the morning and early afternoon, but then decrease with increasing hour of the day after 13:00 h ADT. The magnitude of surface-directed vertical excursions was reduced during spring tide periods, when current velocities are highest. By comparison, the magnitude of slopedirected excursions was greater during spring tide periods and reduced during neap tide periods. Eight fish were at liberty for 42 to $44 \mathrm{~d}$ and 1 for $65 \mathrm{~d}$. Two of the tagged males displayed nest guarding behavior for the majority of their time at liberty. Depths for these 2 males (115 to $117 \mathrm{~m}$ ) were much deeper than previously observed for Atka mackerel spawning grounds. Given that Atka mackerel are more likely to be on the bottom during the night and less likely during the day, the variance of abundance estimates from bottom trawl surveys may be reduced by accounting for these diel differences.
\end{abstract}

KEY WORDS: Diurnal migration · Vertical migration · Atka mackerel · Archival tag

\section{INTRODUCTION}

Atka mackerel Pleurogrammus monopterygius, like other Hexagrammids, do not have a swimbladder and are therefore difficult to detect with hydroacoustic methods. Consequently, their vertical migration and diel behavior are poorly understood. Unlike other Hexagrammids, which are generally solitary and bottom-dwelling, Atka mackerel are thought to undergo extended vertical movements off the bottom (Orlov

*E-mail: dan.nichol@noaa.gov
1997), and have been captured in high concentrations more associated with schooling fish. The spawning habits of Atka mackerel influence their vertical movement patterns. Male Atka mackerel, which exhibit a bright yellow color during the spawning season, are known to guard egg nests until hatching occurs (Gorbunova 1962, Rutenberg 1962, Zolotov 1993). Lauth verified the existence of Atka mackerel nests and nest guarding behavior by males in Seguam Pass with underwater video and SCUBA diving observations (R. Lauth pers. comm.). Spawning can occur from July through October (McDermott \& Lowe 1997), with eggs 
taking 40 to $45 \mathrm{~d}$ to hatch after spawning (Gorbunova 1962).

Atka mackerel is one of the most abundant fish species in the Aleutian Islands region in the North Pacific Ocean, and they have been identified as an important food source for Steller sea lions (Merrick et al. 1997), which are currently listed as endangered. From 1997 to 1999 , the mean annual catch was 58888 metric tons (t), but over $100000 \mathrm{t}$ were harvested in 1996 (Lowe \& Fritz 2000). Fisheries resource assessment scientists at the Alaska Fisheries Science Center (AFSC) currently estimate the abundance of Atka mackerel from a multi-species bottom trawl survey conducted in the Aleutian Islands with sampling during daylight hours only. This groundfish survey was conducted in 1980, 1983 and 1986 and triennially from 1991 to present. While it has been an effective survey for the majority of groundfish species involved, the resulting abundance estimates for Atka mackerel have been highly variable (Lowe \& Fritz 2000). One of the main causes of this variability is the patchy distribution of Atka mackerel. Another source of variability may be the error associated with vertical movement patterns that reduce the fish's availability to the bottom trawl gear. To better understand the temporal change in vulnerability of Atka mackerel to both Steller sea lion foraging and to the bottom trawl survey, we examined the diurnal vertical migrations of Atka mackerel using archival tags, and relate these movements to light intensity and current velocity.

\section{MATERIALS AND METHODS}

Tagging procedure. Atka mackerel were initially captured during 2 bottom trawl tows made on 23 July 2000 aboard the chartered FV 'Morning Star' in Seguam Pass, Alaska (Fig. 1). Tow durations were kept short $(<15 \mathrm{~min})$ in order to minimize injury to fish. Fish were held briefly in tanks plumbed with a continuous flow of fresh seawater. A total of 117 fish, 66 fish from the first tow (Haul 4) at $119 \mathrm{~m}$ bottom depth and 51 fish from the second (Haul 7) at $110 \mathrm{~m}$ bottom depth, were tagged with archival tags and released on the same day. Fish were measured to the nearest $\mathrm{cm}$ fork length (FL) and released within $3.1 \mathrm{~km}$ of the capture location.

Archival tags were externally attached just below the anterior section of the dorsal fin. Fish were secured in a V-shaped cradle, and paired 18 gauge hypodermic needles were inserted through the fish. Stainless-steel wire (0.02 gauge, $0.5 \mathrm{~mm}$ diameter) was fed through the tag and then through the open end of the hypodermic needles. After removing the hypodermic needles, the stainless-steel wire ends were fed through a pink plastic oval and secured with stainless-steel connector sleeves This procedure took approximately $3 \mathrm{~min}$ per fish.

A tag reward program was implemented to retrieve tagged fish. This program was conducted in association with an ongoing spaghetti tag project for Atka mackerel in Seguam Pass (Fritz et al. 2001). A directed bottom trawl fishery for Atka mackerel in Seguam Pass, involving 8 catcher-processing vessels, occurred from 1 to 5 September 2000. Recovered archival tags were given to on-board fishery observers. An NMFSsponsored tag recovery cruise aboard the FV 'Seafisher' from 16 to 29 September 2000 was also involved in tag recovery.

Prior to the tagging survey, we conducted a control experiment involving 2 Atka mackerel and 10 kelp greenling Hexagrammos decagrammus which were tagged externally with dummy tags. Dummy tags were of similar size, weight and buoyancy to the actual tags used. The control experiment was used to evaluate and refine the tagging procedure, and to monitor fish survival after tagging. The 2 Atka mackerel were collected aboard the NOAA ship 'Miller Freeman' north of Dutch Harbor, Alaska, in March 2000, and the greenlings were captured in April 2000 off Kodiak, Alaska. All fish were held in one $2.4 \mathrm{~m}$ diameter (4353 1 capacity) tank at the NMFS wet-lab facility in Kodiak. The tank was equipped with flow-through water from Chiniak Bay, Kodiak. Fish were held for more than 1 mo prior to tagging and were held in the same tank for more than 6 mo after tagging.

Tag specifications. The archival tags (Tag logger, Model RL-42, Conservation Devices) recorded both pressure (depth) and temperature. Each tag measured $8 \times 16 \times 27 \mathrm{~mm}$ and weighed approximately $4.1 \mathrm{~g}$ in air and $1.8 \mathrm{~g}$ in water. In addition, tags measured 16384 samples each of temperature and pressure at 8-bit resolution. Tags have a time extension memory management function that results in a decrease in the frequency of collection as the time at liberty increases; each time the tag memory fills, alternate depthtemperature values are overwritten and the sampling intervals double. Tags, therefore, continue to record regardless of the time at liberty. Tags at liberty for $40 \mathrm{~d}$ recorded depth and temperature every $3.75 \mathrm{~min}$. Depth (pressure) was recorded to a maximum of $320 \mathrm{~m}$ and tag depth recording range automatically re-scaled when depths exceeded $80 \mathrm{~m}$ and again when depths exceeded $160 \mathrm{~m}$. Accuracy of depth recordings was $<1 \%$ of each scale range ( 0 to 80,0 to 160,0 to $320 \mathrm{~m}$ ). Temperatures were recorded with an average of $0.2^{\circ} \mathrm{C}$ resolution. Battery life was rated at $3 \mathrm{yr}$. Tag data were optically transmitted from a light-emitting diode within the tag to an optical reader attached to a computer, and were assigned time stamps during the 
download process and standardized to Alaska daylight time (ADT; GMT - 8).

Light intensity and current data. A light sensor (timed data recorder, model Mk8, Wildlife Computers) was deployed approximately $32 \mathrm{~km}$ west of the tag release site on 22 July 2000 at $150 \mathrm{~m}$ bottom depth, and was retrieved on 27 September 2000. This location was within a commercial trawl exclusion area designated as critical habitat for the Steller sea lion, and was chosen to avoid disturbance of the sensor by commercial fishing efforts. The sensor was fastened inside a $2.4 \times$ $2.4 \times 0.9 \mathrm{~m}$ crab pot frame with no webbing and was released with $384 \mathrm{~m}$ of line with two $36 \mathrm{~cm}$ floats and one $30 \mathrm{~cm}$ hard float at the surface. Light intensity was recorded every $60 \mathrm{~s}$. Light readings from the light sensor were post-calibrated to $\mu \mathrm{mol}$ photons $\mathrm{m}^{-2} \mathrm{~s}^{-1}$ by comparing light-levels with an IL 1700 Research Radiometer (International Light) in the laboratory. A linear regression equation $\left(\mathrm{R}^{2}=0.97\right)$ was used to convert relative values from the light sensor to $\mu \mathrm{mol}$ photons $\mathrm{m}^{-2} \mathrm{~s}^{-1}$. We note that these light data indicate light intensity at a depth of $150 \mathrm{~m}$ and not necessarily the light intensity at the depths which individual fish resided. One archival tag was also placed on the light meter apparatus to collect depth information used to illustrate the tidal cycling.

Current velocity data were estimated with nautical software (Tide and Currents Pro for Windows, Ver. 2.5b), which uses NOAA harmonic summation data from current/tide meters and tide correction tables. Predicted values of current velocity for Fenimore Pass, approxi- mately $167 \mathrm{~km}$ west of Seguam Pass, were used as a proxy for current velocity in Seguam Pass (see 'Results').

Analysis. Diel patterns were examined from tag depth recordings for each tag and plotted against time. Light, temperature and current velocity (disregarding direction) data were then overlaid for comparison.

Daily patterns were examined using a multiple linear regression model to evaluate the combined effects of light intensity (mol photons $\mathrm{m}^{-2} \mathrm{~s}^{-1}$ ), hour of day and current velocity (knots) on the occurrence of vertical excursions. Vertical excursions were defined as the distance above or below the depth at which fish settled to the bottom within a $24 \mathrm{~h}$ period (see 'Results' for a more detailed description). 'Fish activity' was defined as the proportion of vertical excursions greater than $5 \mathrm{~m}$ above this settling depth within a set period of time

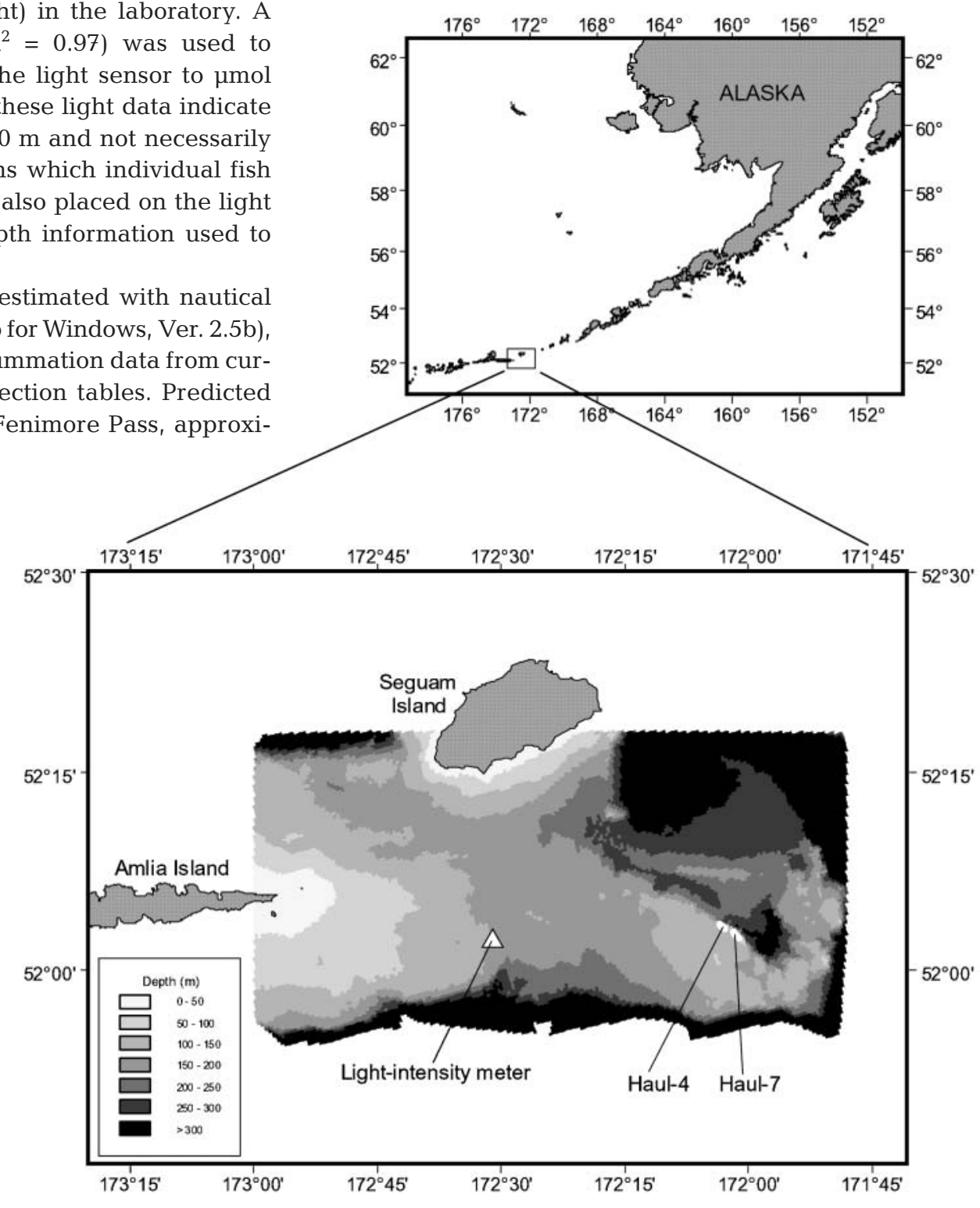

Fig. 1. Pleurogrammus monopterygius. Initial capture locations and tagging with archival (data storage) tags on 23 July 2000 

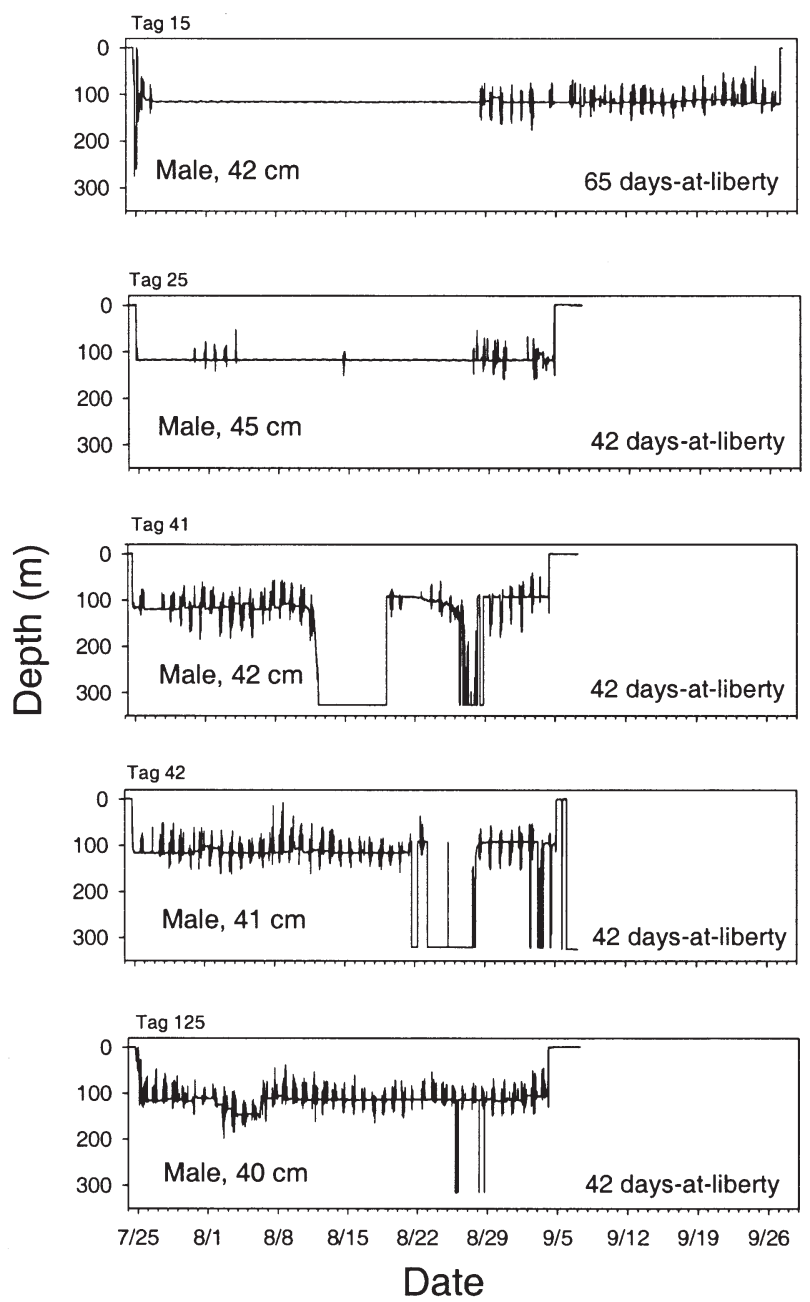

(2 h). Fish activity was then regressed (S-PLUS 2000) against light intensity, hour of day and current velocity as follows:

$$
\begin{aligned}
Y_{i j}=\mu & +\operatorname{tag}_{i}+\beta(\text { light })_{i j} \\
& +\phi_{1}(\text { hour })_{i j}+\phi_{2}\left(\text { hour }^{2}\right)_{i j} \\
& +\gamma(\text { current })_{i j}+\theta(\text { light } \times \text { hour })_{i j}+\epsilon_{i j}
\end{aligned}
$$

where $Y_{i j}=\arcsin \left(\sqrt{P R O P_{i j}}\right)$ and $P R O P_{i j}$ is the proportion of fish activity for the ith tag during the $j$ th $2 \mathrm{~h}$ interval over a $24 \mathrm{~h}$ day; $\mu$ is the grand mean; $\operatorname{tag}_{i}$ is the tag number for the ith tag, a discrete variable identifying each of 9 tags; light is the ln(light intensity in $\mu \mathrm{mol}$ photons $\mathrm{m}^{-2} \mathrm{~s}^{-1}$ ), a continuous variable; current is the current velocity in knots (disregarding direction), a continuous variable; hour is the hour of the day in $2 \mathrm{~h}$ increments; a continuous variable; and light $\times$ hour is the interaction between light and hour $\in_{i j}$ represents a normally distributed error (residuals); and $\beta, \phi_{1}, \phi_{2}, \gamma, \theta$ are coefficients.

Data were limited to light levels equal to and above the minimum light level where fish activity was evi-
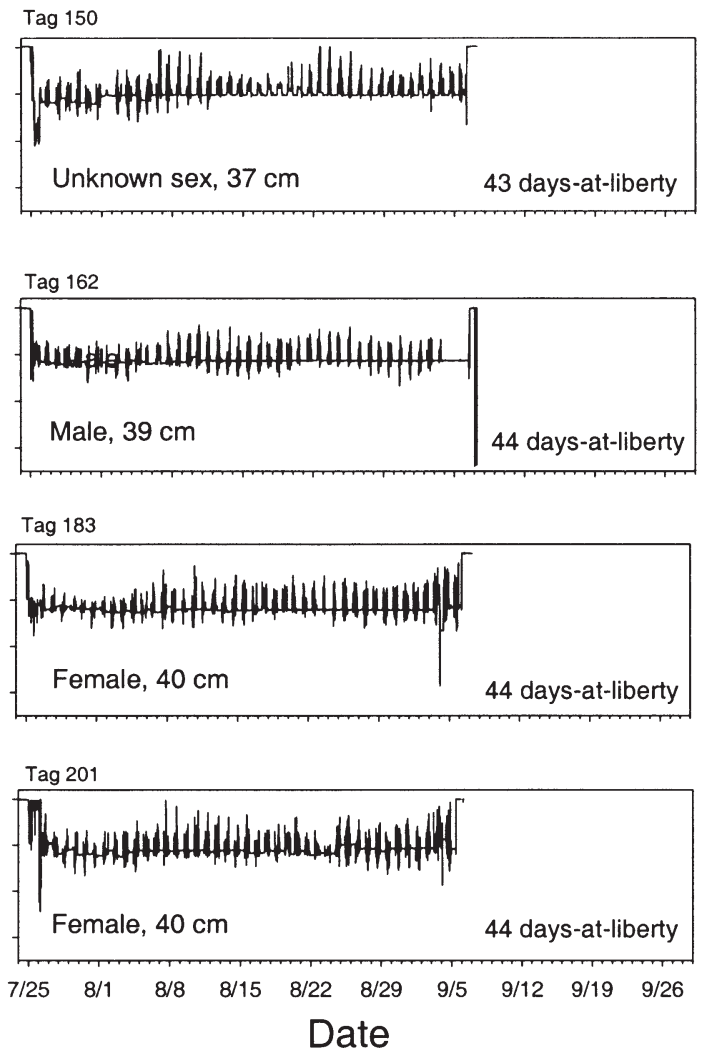

Fig. 2. Pleurogrammus monopterygius. Depth recordings from 9 Atka mackerel tagged in 2000. Fish presented on the left were initially captured from an apparent nesting site (Haul 4) and were mostly brightly yellow-colored males. Fish presented on the right were initially captured from a tow (Haul 7) consisting of a mix of both females and males without spawning colors

dent $\left(1.67 \times 10^{-5} \mu \mathrm{mol}\right.$ photons $\mathrm{m}^{-2} \mathrm{~s}^{-1}$ at $\left.150 \mathrm{~m}\right)$. Hour was included as a second-order polynomial, and hour values were grouped into $2 \mathrm{~h}$ intervals (e.g. hour $10=$ period between 09:00 and 10:59 h). An arcsine transformation was computed to normalize the error distribution $\left(\in_{i j}\right)$ for the proportion of activity (Zar 1984). This analysis excluded periods of presumed nest-guarding, as well as periods when fish underwent deep-dives beyond the $320 \mathrm{~m}$ depth limit of the tags. These data were initially explored using general additive model fits (GAM; S-PLUS 2000) to determine appropriate functions (e.g. linear, nonlinear) for each of the parameters.

Vertical excursions were also expressed in terms of maximum distance $(\mathrm{m})$ above their settling (bottom) depth (surface-directed excursions) and the maximum distance below their settling depth (slope-directed excursions). Two multiple linear regression models were constructed as above, but substituting $Y_{i j}$ with the maximum surface-directed distance and maximum slope-directed distance. 


\section{RESULTS}

\section{Control tagging}

No mortality or tag loss occurred for the 2 Atka mackerel and 10 kelp greenling during the control experiment. Fish showed no apparent behavioral effect or physical injury from the attached tag for the 6 mo that they were held in the laboratory.

\section{Tag recovery}

Nine data storage tags were recovered, 8 during the fishery in Seguam Pass and 1 during the NMFS sponsored tag-recovery cruise in Seguam Pass (Fig. 2). Recovered Atka mackerel ranged from 37 to $45 \mathrm{~cm}$ FL. Five fish (all males) were from the first release site (Haul 4), and 4 (1 male, 2 females, 1 unknown sex) were from the second release site (Haul 7; Fig. 1). Eight fish were at liberty for 42 to $44 \mathrm{~d}$ and 1 for $65 \mathrm{~d}$.

Two males displayed what appeared to be nestguarding behavior with virtually no vertical movement for the majority of the time they were at liberty (Tags
15 and 25; Fig. 2). This behavior occurred at depths from 115 to $117 \mathrm{~m}$. Also, 3 other males (Tags 41, 42 and 125) underwent deep dives in excess of the $320 \mathrm{~m}$ depth recording limit for the tags (Fig. 2). These 5 males were bright yellow (spawning color) when released.

Validation of current velocity data. Estimates of tidal fluctuations from Fenimore Pass coincided well with tidal fluctuations recorded by archival tags recovered from nest-guarding males in Seguam Pass (Fig. 3). Although the amplitudes of the predicted tide for Fenimore Pass were less than the amplitudes recorded by the fish tag, the periodicity and the relative magnitude (e.g. spring to neap tide) of the exchanges matched well. Given the similarity in tidal cycles here, values of current velocity from Fenimore Pass were used as a relative measure for current velocity in Seguam Pass.

Diel behavior. Vertical movements were strongly associated with light intensity and the time of day. Virtually all vertical movements occurred during daylight hours with no movement at night (Figs. 4 \& 5). Vertical movements occurred when light intensity levels at $150 \mathrm{~m}$ were greater than $7.31 \times 10^{-5} \mu \mathrm{mol}$ photons $\mathrm{m}^{-2}$
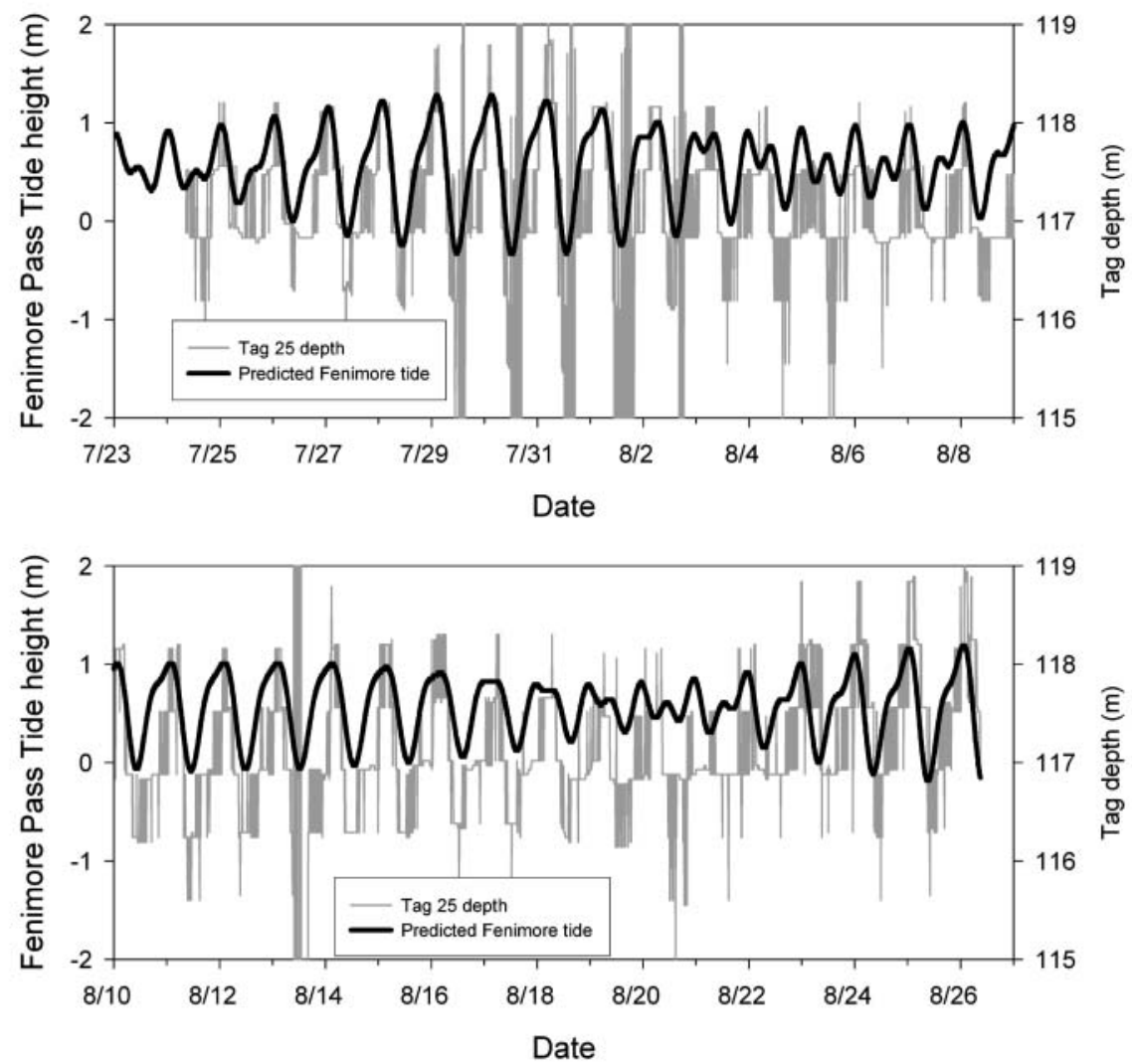

Fig. 3. Predicted values of tide height $(\mathrm{m})$ from Fenimore Pass (black line) as compared to depth values (m) recorded from archival Tag 25 (gray line) attached to a nest-guarding male Atka mackerel. Because the fish did not undergo vertical movements for the majority of the time illustrated here, except from 28 July to 3 August and 13 August 2000, tag depth fluctuations indicate 


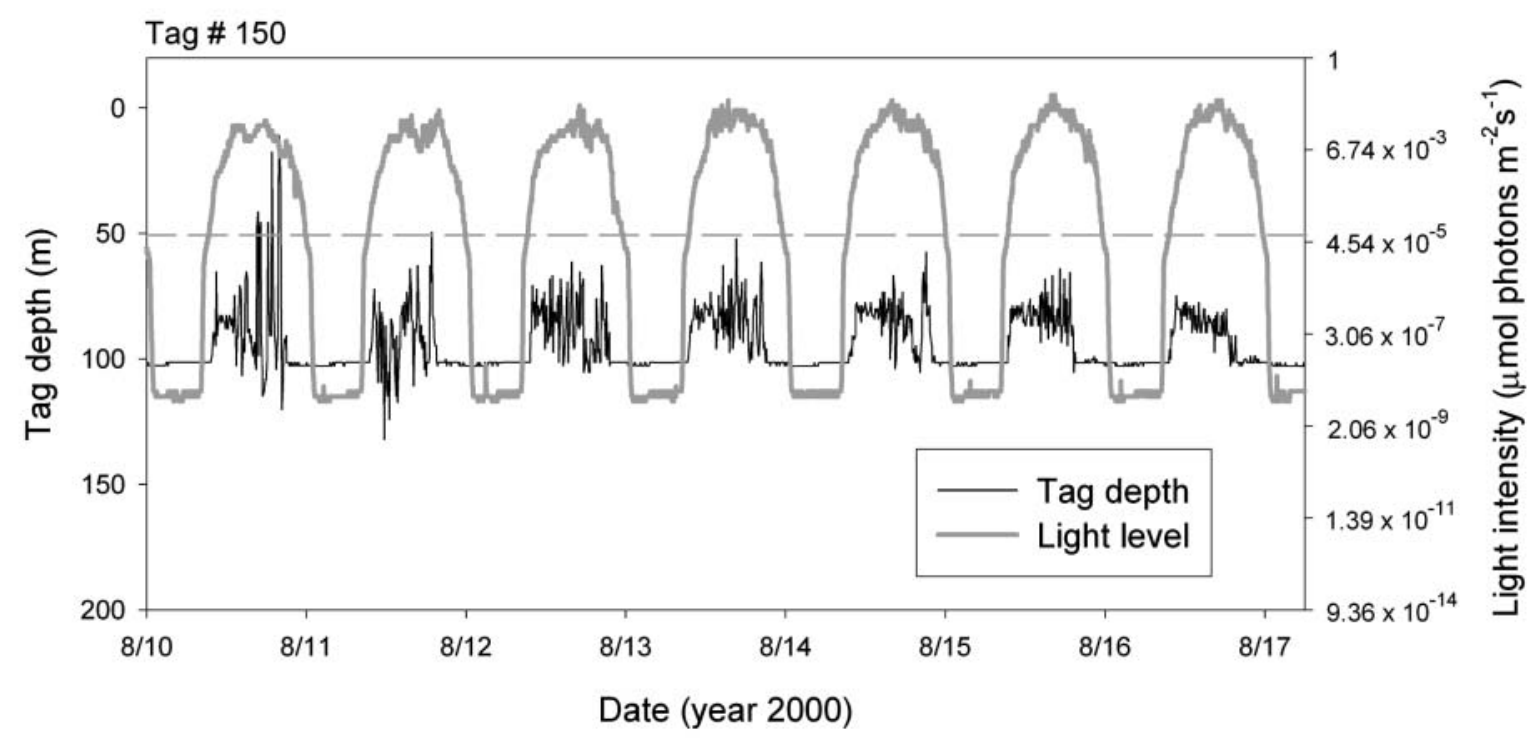

Fig. 4. Pleurogrammus monopterygius. Typical diel vertical movement pattern (black line) over 1 wk (Tag 150), with light inten-

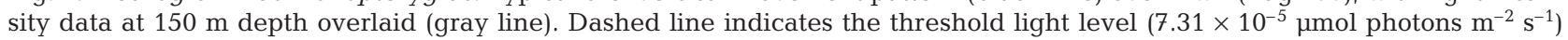
above which vertical movements occur

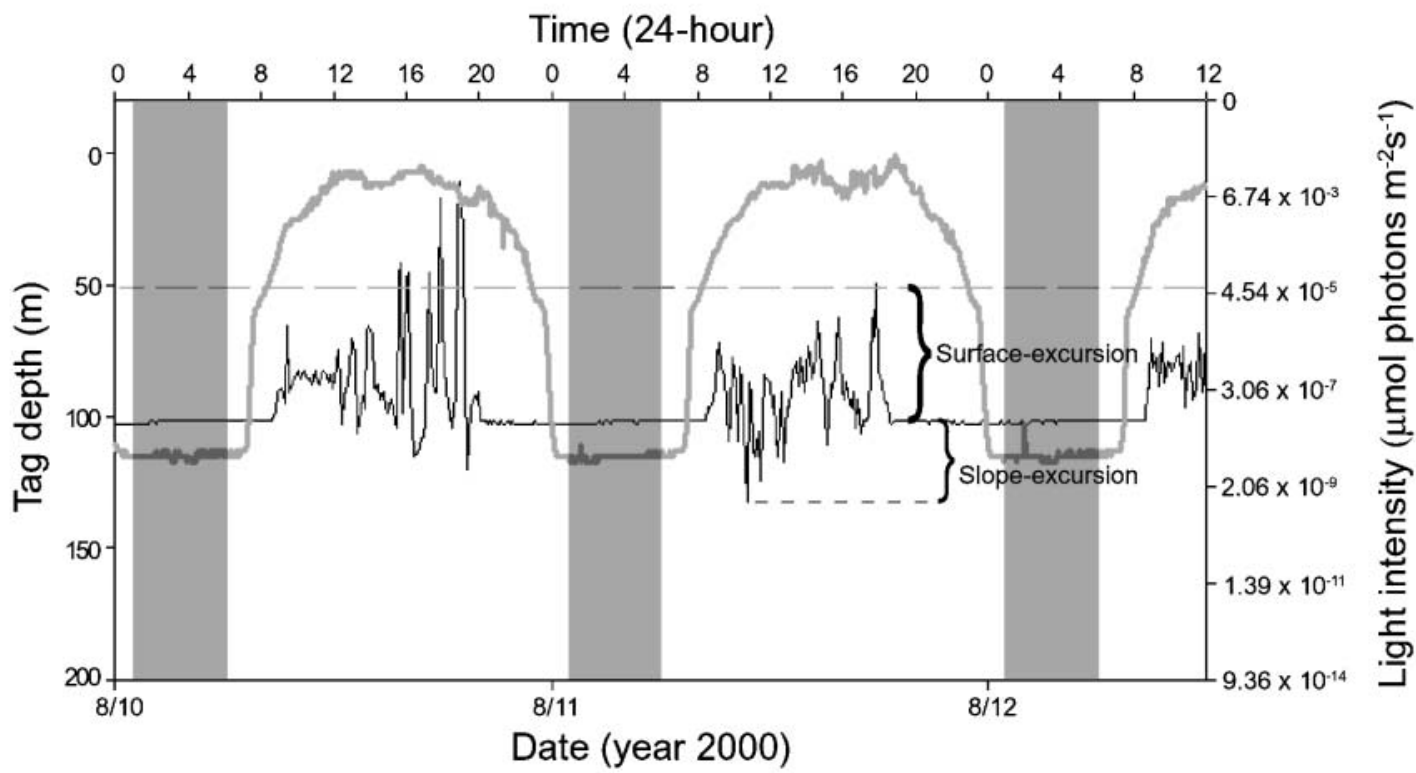

Fig. 5. Pleurogrammus monopterygius. Vertical excursions defined as the distance above (surface-directed) or below (slopedirected) the depth at which Atka mackerel settled during the night (Tag 150). Light intensity is overlaid in gray. Shaded area indicates the time between 01:00 and 06:00 h ADT, within which the nighttime bottom depth was defined for each $24 \mathrm{~h}$ period.

Dashed line indicates the threshold light level $\left(7.31 \times 10^{-5} \mu \mathrm{mol}\right.$ photons $\left.\mathrm{m}^{-2} \mathrm{~s}^{-1}\right)$ above which vertical movements occur

$\mathrm{s}^{-1}$, or approximately between 08:00 and 23:00 h ADT during August. These times correspond to sunrise (08:14 $\mathrm{h}$ ADT) and sunset $(22: 51 \mathrm{~h}$ ADT) for the Seguam Pass area during this period as calculated by the US Naval Observatory, Astronomical Applications Department (pers. comm.).

Definition of vertical excursion and 'fish activity'. Vertical excursions were defined as the net surface- directed (+) or slope-directed (-) distance above or below the depth at which an individual settled during the night. The nighttime depths were clearly bottom depths given that they corresponded to bathymetry data collected during the tagging cruise as well as the bottom trawl depths recorded by the recovery vessels. For each day, the nighttime settling depth was calculated as the average nighttime depth before and after daytime ac- 


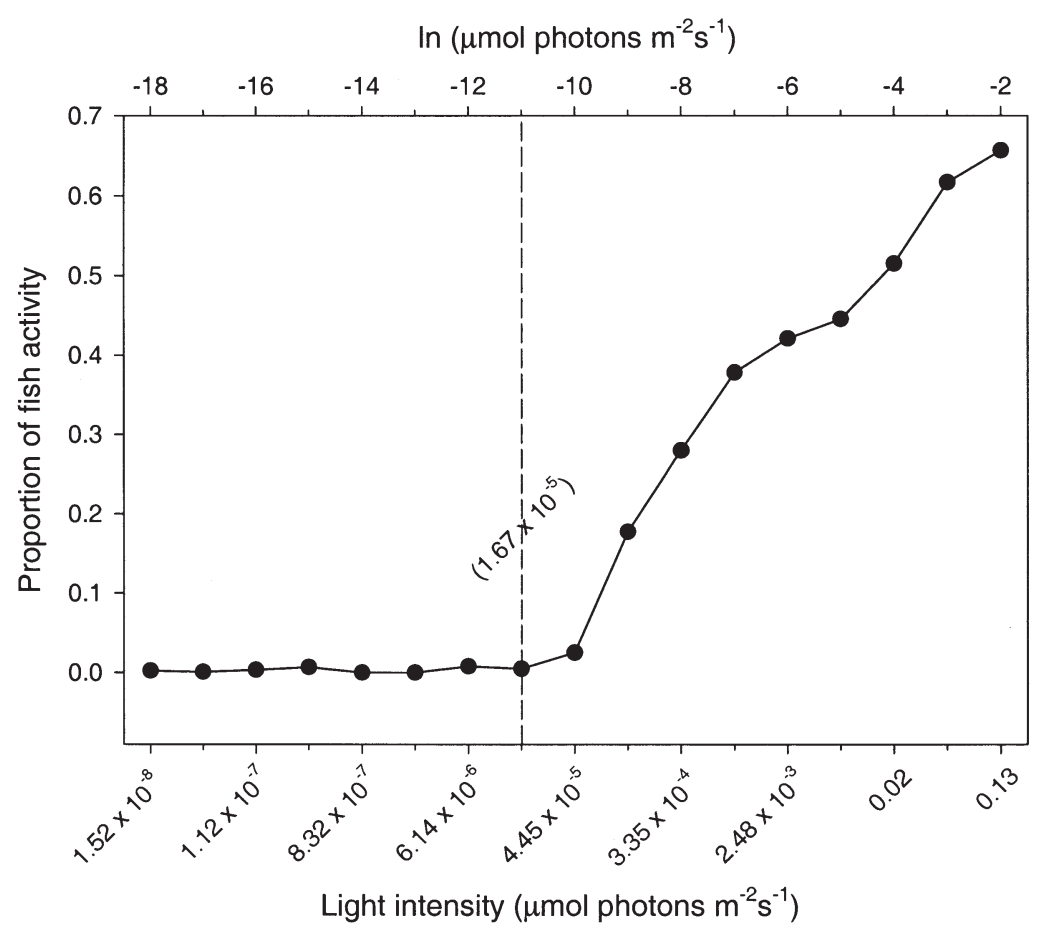

Fig. 6. Pleurogrammus monopterygius. Proportion of fish activity with respect to light intensity. Data are pooled for 9 tagged fish with light intensity grouped as 1 unit increments (e.g. $-18=-18$ to -18.99 , top axis). Light intensity at $150 \mathrm{~m}$ depth is expressed linearly on the top axis with corresponding anti-log scale values on the bottom axis. Fish activity is expressed as the proportion of vertical excursions greater than $5 \mathrm{~m}$ from their nighttime settling depth. Analyses of daytime fish activity excludes data where light intensity was $>1.67 \times 10^{-5} \mu \mathrm{mol}$ photons $\mathrm{m}^{-2} \mathrm{~s}^{-1}$
(Fig. 7). According to both the light sensor deployed in Seguam Pass and the US Naval Observatory (pers. comm.), the hour of maximum light intensity during August occurred at approximately 15:30 h ADT; therefore, despite the availability of the highest levels of light intensity while fish were at liberty, fish activity tended to decrease as the afternoon progressed. Fish activity was also significantly related to current velocity ( $p=$ 0.0045); however, because the actual effect on fish activity was negligible compared to the other variables, it was excluded from the model.

\section{Magnitude of surface-directed and slope-directed vertical excursions}

The magnitude of daytime surfacedirected vertical excursions, or the maximum vertical distance above the nighttime settling depth, was significantly related to light intensity, hour of the day and current velocity (Table 2, Fig. 8a). As with fish activity, the magnitude of surface-directed excursions generally increased with increasing light intensity until approximately 13:00 h ADT, after tivity (Fig. 5). The period between 01:00 and 06:00 h ADT was chosen as the nighttime settling period.

Fish activity was defined as the proportion of vertical excursions (+ and -) greater than $5 \mathrm{~m}$ within a $2 \mathrm{~h}$ period. Because virtually no fish activity occurred at light intensity levels less than $1.67 \times 10^{-5} \mu \mathrm{mol}$ photons $\mathrm{m}^{-2}$ $\mathrm{s}^{-1}$ (Fig. 6), subsequent analyses of fish activity exclude these nighttime periods. Subsequent analyses also exclude days when the nighttime settling depths differed by more than $5 \mathrm{~m}$ before and after each day.

\section{Fish activity during daylight hours}

Fish activity was significantly related to light intensity $(\mathrm{p}<0.0001)$ and hour of the day $(\mathrm{p}<0.0001$; Table 1). A significant interaction effect between light and hour ( $p<0.0001)$ indicated that the fish activity response to light intensity was different at different times of the day. The likelihood of fish activity increased with increasing light from morning (08:00 $\mathrm{h}$ ADT) until about 13:00 h ADT, after which the likelihood decreased with increasing hour of the day
Table 1. Multiple linear regression analysis results of Atka mackerel vertical 'activity' during daytime, as related to light intensity $\ln \left(\mu \mathrm{mol}\right.$ photons $\left.\mathrm{m}^{-2} \mathrm{~s}^{-1}\right)$ at $150 \mathrm{~m}$ depth and hour of day. Activity is expressed as the proportion of vertical excursions greater than $5 \mathrm{~m}$ from their nighttime settling depth. Analysis excludes nest-guarding periods, isolated deepdives, periods when light intensity was $\leq 1.67 \times 10^{-5} \mu \mathrm{mol}$ photons $\mathrm{m}^{-2} \mathrm{~s}^{-1}$, and days when the nighttime settling depth differed by $\geq 5 \mathrm{~m}$ between 2 successive nights. Tag is a discrete variable, and light and hour terms are continuous. Model $F=$ 189.9, $\mathrm{df}=12,2059, \mathrm{R}^{2}=0.51$

\begin{tabular}{|c|c|c|c|c|c|}
\hline Variable & Symbol & 1 Estimate & $\mathrm{SE}$ & $t$-value & $p>t$ \\
\hline $\operatorname{Tag}_{15}$ (intercept) & $\mu$ & 43.41 & 4.38 & 9.90 & $<0.0001$ \\
\hline $\operatorname{Tag}_{25}$ & & 33.58 & 2.84 & -3.46 & 0.0006 \\
\hline $\mathrm{Tag}_{41}$ & & 46.98 & 2.21 & 1.61 & 0.1072 \\
\hline $\mathrm{Tag}_{42}$ & & 47.74 & 2.13 & 2.03 & 0.0421 \\
\hline $\operatorname{Tag}_{125}$ & & 47.90 & 2.06 & 2.18 & 0.0294 \\
\hline $\operatorname{Tag}_{150}$ & & 61.34 & 1.20 & 8.96 & $<0.0001$ \\
\hline $\operatorname{Tag}_{162}$ & & 46.46 & 1.98 & 1.53 & 0.1254 \\
\hline $\operatorname{Tag}_{183}$ & & 55.33 & 2.04 & 5.85 & $<0.0001$ \\
\hline $\operatorname{Tag}_{201}$ & & 55.73 & 2.18 & 7.04 & $<0.0001$ \\
\hline Light & $\beta$ & 11.23 & 0.85 & 13.15 & $<0.0001$ \\
\hline Hour & $\phi_{1}$ & 1560.23 & 82.84 & -18.83 & $<0.0001$ \\
\hline$(\text { Hour })^{2}$ & $\phi_{2}$ & -472.17 & 65.73 & -7.18 & $<0.0001$ \\
\hline Light $\times$ Hour & $\theta$ & -0.56 & 0.04 & -13.23 & $<0.0001$ \\
\hline
\end{tabular}




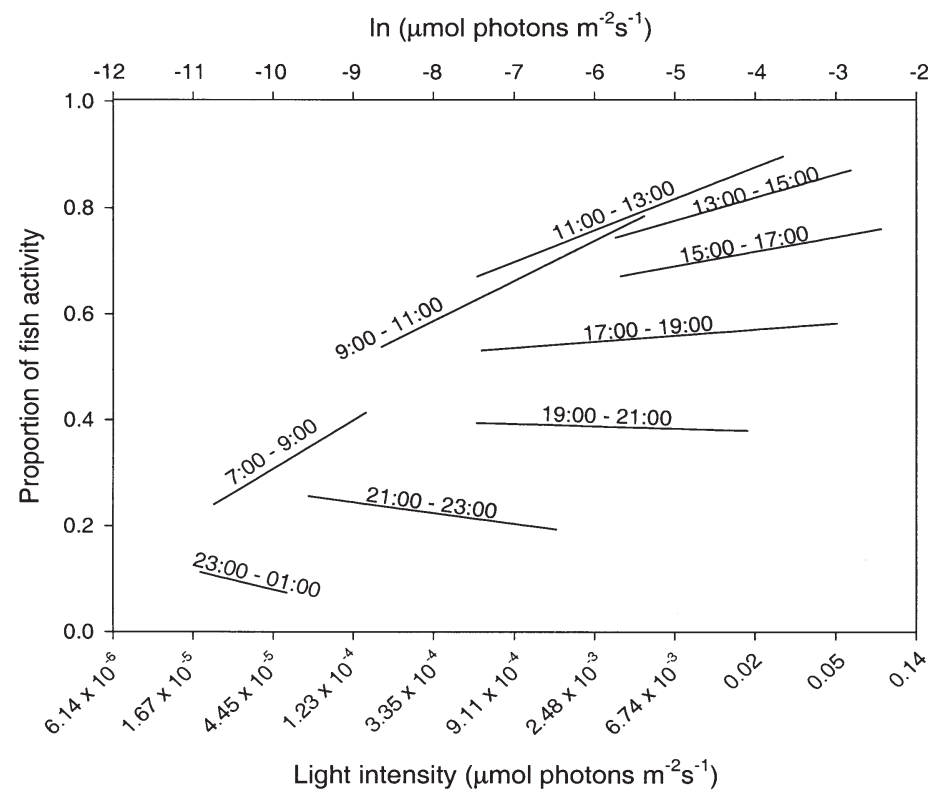

Fig. 7. Pleurogrammus monopterygius. Fish activity as a function of light intensity (at $150 \mathrm{~m}$ depth) at different times of the day for Tag 150. Predicted values from the multiple linear regression model $Y_{i j}=\mu+\operatorname{tag}_{i}+(\text { light })_{i j}+\phi_{1}(\text { hour })_{i j}+\phi_{2}\left(\text { hour }^{2}\right)_{i j}+\theta(\text { light } \times \text { hour })_{i j}+\epsilon_{i j}$ where $Y_{i j}$ is the proportion of fish activity for the ith tag within each $2 \mathrm{~h}$ period (hour) of the the $j$ th day

which excursion distances decreased as the afternoon progressed (Fig. 8a). In addition, greater current velocities tended to negatively affect a fish's surfacedirected vertical excursions. Within a particular time of day (e.g. $2 \mathrm{~h}$ period) and light intensity level, maximum vertical excursion distances were shorter at greater current velocities (Fig. 8a).

The magnitude of slope-directed vertical excursions was similarly affected by light intensity and time of day (Table 3, Fig. 8b). However, the magnitude of slopedirected excursions were oppositely affected by current velocity. Within a particular time of day and light intensity level, the maximum distance of slopedirected vertical excursions actually increased during periods of greater current velocities (Fig. 8b).

Current velocity effects on the magnitude of vertical excursions were most apparent during periods of spring and neap tides. Despite the fact that current velocity effects are likely to be unique for each fish depending on their location, for most of the tagged fish, the magnitude of surface-directed excursions was less during days within spring tide periods and higher during neap tide periods when current velocities are lower (Fig. 9). We found the opposite relationship for slope-directed excursions; the magnitude of slope-directed excursions increased during spring tide periods and decreased during neap tide periods (Fig. 10).

\section{Beginning and ending times of daily vertical movements}

Times at which vertical excursions began were relatively constant for each fish compared with times at which fish settled back to the bottom, which were much more variable (Fig. 11). A current or tide effect was apparent for 1 fish (Tag 150), in which vertical movements began later in the day during spring tide periods as compared to neap tide periods. Times at which vertical excursions began were slightly later in September compared to beginning times in July (Fig. 11), indicating that as the day length shortens, so does the period of daytime activity.

\section{DISCUSSION}

\section{Diel behavior}

Tag depth recordings from 9 Atka mackerel captured in Seguam Pass, Alaska, indicated a clear diel movement pattern, with vertical movements occurring only during daylight hours. Nocturnal vertical movements were almost nonexistent. Based on bathymetry data for the area

Table 2. Multiple linear regression analysis results of Atka mackerel maximum surface-directed vertical excursions, as related to light intensity $\ln \left(\mu \mathrm{mol}\right.$ photons $\left.\mathrm{m}^{-2} \mathrm{~s}^{-1}\right)$ at $150 \mathrm{~m}$ depth, hour of day and current velocity (disregarding direction). Vertical excursion is expressed as the maximum surface-directed distance within a $2 \mathrm{~h}$ period. Analysis excludes nest-guarding periods, isolated deep-dives, periods when light intensity was $\leq 1.67 \times 10^{-5} \mu \mathrm{mol}$ photons $\mathrm{m}^{-2} \mathrm{~s}^{-1}$, and days when the nighttime settling depth differed by $\geq 5 \mathrm{~m}$ between 2 successive nights. Tag is a discrete variable, and light, hour and velocity terms are continuous. Model $F=63.99, \mathrm{df}=$ $13,1875, R^{2}=0.31$

\begin{tabular}{|c|c|c|c|c|c|}
\hline Variable & Symbol & 1 Estimate & SE & $t$-value & $p>t$ \\
\hline $\operatorname{Tag}_{15}$ (intercept) & $\mu$ & 26.25 & 3.61 & 7.27 & $<0.0001$ \\
\hline $\operatorname{Tag}_{25}$ & & 28.28 & 2.43 & 0.84 & 0.4034 \\
\hline $\operatorname{Tag}_{41}$ & & 28.08 & 1.94 & 0.95 & 0.3448 \\
\hline $\operatorname{Tag}_{42}$ & & 30.54 & 1.85 & 2.32 & 0.0202 \\
\hline $\operatorname{Tag}_{125}$ & & 30.99 & 1.78 & 2.66 & 0.0078 \\
\hline $\operatorname{Tag}_{150}$ & & 38.03 & 1.73 & 6.82 & $<0.0001$ \\
\hline $\operatorname{Tag}_{162}$ & & 32.29 & 1.76 & 3.43 & 0.0006 \\
\hline $\operatorname{Tag}_{183}$ & & 37.61 & 1.78 & 6.38 & $<0.0001$ \\
\hline $\operatorname{Tag}_{201}$ & & 38.11 & 1.89 & 6.28 & $<0.0001$ \\
\hline Light & $\beta$ & 2.78 & 0.74 & 3.77 & $<0.0001$ \\
\hline Hour & $\phi_{1}$ & -365.49 & 66.02 & -5.54 & $<0.0001$ \\
\hline$(\text { Hour })^{2}$ & $\phi_{2}$ & -316.73 & 51.45 & -6.16 & $<0.0001$ \\
\hline Current & $\lambda$ & -1.67 & 0.33 & -5.12 & $<0.0001$ \\
\hline Light $\times$ Hour & $\theta$ & -0.11 & 0.04 & -2.93 & 0.0034 \\
\hline
\end{tabular}


(a)

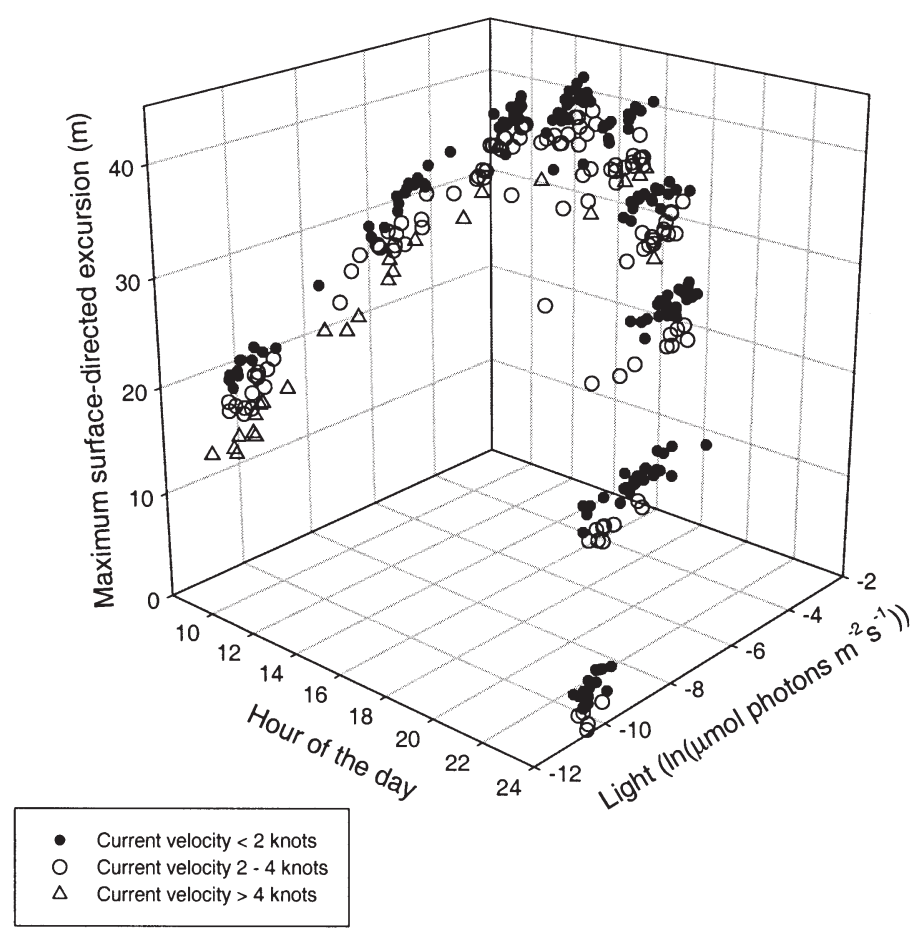

(b)

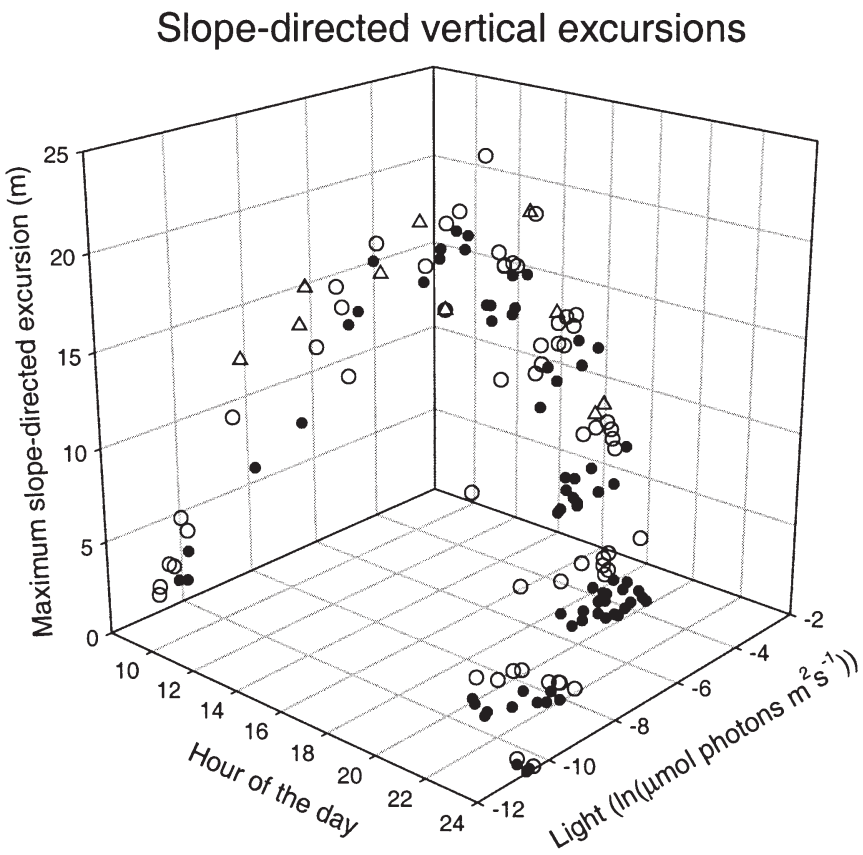

Fig. 8. Pleurogrammus monopterygius. Maximum surface-directed (a) and maximum slope-directed (b) vertical excursion distance from the nighttime settling depth, as a function of light intensity (at $150 \mathrm{~m}$ depth), hour of the day and current velocity for Tag 150. Predicted values from the multiple linear regression models $Y_{i j}=\mu+\operatorname{tag}_{i}+\beta(\text { light })_{i j}+\phi_{1}(\text { hour })_{i j}$ $+\phi_{2}\left(\text { hour }^{2}\right)_{i j}+\gamma(\text { current })_{i j}+\theta(\text { light } \times \text { hour })_{i j}+\epsilon_{i j}$, where $Y_{i j}$ is the maximum surface (top) or slope (bottom) directed vertical excursion distance within each $2 \mathrm{~h}$ period (hour) of the $j$ th day
(Fig. 1), and the bottom depths at which fish were released and re-captured, fish were clearly settled on the bottom during the night. These depths typically ranged from 100 to $120 \mathrm{~m}$ (Fig. 2). Downward excursions beyond these nighttime depths indicated excursions down a slope. Bathymetry data indicated that these fish settled on the edge of a slope that descends to as deep as $410 \mathrm{~m}$ bottom depth (Fig. 1). Deep excursions beyond the $320 \mathrm{~m}$ depth limit of the tags, as several fish underwent (Fig. 2), were therefore possible within a short distance of the fish's nighttime settling depth.

Atka mackerel consistently returned to the same depth each night (Figs. 4 \& 5). This suggests that individuals return to the same location or home site before night. Longer-range inshore and offshore migrations of Atka mackerel, before and after the spawning season (Cobb 1907, Zolotov 1993), may occur during other times of the year. Given the regularity of their diurnal pattern of vertical movement, we suspect that Atka mackerel continue a diurnal pattern throughout the year. We disagree with the assertion that Atka mackerel are mostly pelagic after the spawning season (Cobb 1907, Zolotov 1981). In fact, due to the reduced day length in winter, Atka mackerel are likely to spend more time on the bottom after the spawning season.

The distinct diurnal vertical migrations of Atka mackerel may influence their availability as a prey item for Steller sea lions. Atka mackerel are the primary prey of Steller sea lions in the central and western Aleutian Islands throughout the year, however, their importance relative to other prey declines in the winter (Fritz \& Lowe 1998, Sinclair \& Zeppelin 2002). One possible explanation for this is that Atka mackerel may be more vulnerable to Steller sea lion predation during daylight hours, when they migrate up into the water column. If this is true, then the shorter day length during winter would offer fewer opportunities for Steller sea lions to encounter Atka mackerel.

\section{Vertical movements during daylight hours}

Daytime movements were significantly related to light intensity, hour of the day and current velocity. Vertical excursions gener- 
Table 3. Multiple linear regression analysis results of Atka mackerel maximum slope-directed vertical excursions, as related to light intensity $\ln \left(\mu \mathrm{mol}\right.$ photons $\left.\mathrm{m}^{-2} \mathrm{~s}^{-1}\right)$ at $150 \mathrm{~m}$ depth, hour of day and current velocity (disregarding direction). Vertical excursion is expressed as the maximum slopedirected distance within a $2 \mathrm{~h}$ period. Analysis excludes nestguarding periods, isolated deep-dives, periods when light intensity was $\leq 1.67 \times 10^{-5} \mu \mathrm{mol}$ photons $\mathrm{m}^{-2} \mathrm{~s}^{-1}$, and days when the nighttime settling depth differed by $\geq 5 \mathrm{~m}$ between 2 successive nights. Tag is a discrete variable, and light, hour and velocity terms are continuous. Model $F=54.85$, df $=$ $13,1580, R^{2}=0.31$

\begin{tabular}{|c|c|c|c|c|c|}
\hline Variable & Symbol & l Estimate & $\mathrm{SE}$ & $t$-value & $\mathrm{p}>t$ \\
\hline $\operatorname{Tag}_{15}$ (intercept) & $\mu$ & 13.06 & 2.18 & 6.00 & $<0.0001$ \\
\hline $\operatorname{Tag}_{25}$ & & 8.76 & 1.95 & -2.21 & 0.0272 \\
\hline $\operatorname{Tag}_{41}$ & & 20.44 & 1.34 & 5.49 & $<0.0001$ \\
\hline $\operatorname{Tag}_{42}$ & & 14.98 & 1.21 & 1.58 & 0.1142 \\
\hline $\operatorname{Tag}_{125}$ & & 12.49 & 1.17 & -0.49 & 0.6262 \\
\hline $\operatorname{Tag}_{150}$ & & 11.07 & 1.25 & -1.59 & 0.1128 \\
\hline $\operatorname{Tag}_{162}$ & & 9.97 & 1.14 & -2.72 & 0.0067 \\
\hline $\operatorname{Tag}_{183}$ & & 11.12 & 1.16 & -1.61 & 0.1075 \\
\hline $\operatorname{Tag}_{201}$ & & 15.19 & 1.22 & 1.74 & 0.0817 \\
\hline Light & $\beta$ & 5.48 & 0.50 & 11.07 & $<0.0001$ \\
\hline Hour & $\phi_{1}$ & -600.87 & 41.11 & -14.62 & $<0.0001$ \\
\hline$(\text { Hour })^{2}$ & $\phi_{2}$ & -95.81 & 27.89 & 3.44 & 0.0006 \\
\hline Current & $\lambda$ & 1.17 & 0.23 & 5.08 & $<0.0001$ \\
\hline Light $\times$ Hour & $\theta$ & -0.30 & 0.03 & -11.59 & $<0.0001$ \\
\hline
\end{tabular}

ally increased in occurrence and magnitude with increasing light intensity; however, as afternoon progressed, excursions often decreased despite a high level of light intensity. Because times at which fish settled to the bottom were inconsistent compared to times at which fish began daily activity (Fig. 11), a factor other than light or time of day must also influence vertical movements.

Food satiation may partly explain why Atka mackerel settle back to the bottom at variable times in the afternoon and evening. Atka mackerel are primarily zooplanktivorous, feeding on prey such as euphausiids and calanoid copepods (Orlov 1997, Yang 1999). They are also visual feeders, and it is likely that they require a threshold level of light to successfully feed upon prey in the water column. Assuming that feeding is the main reason why Atka mackerel undergo vertical movements, it makes sense that after lying dormant during the night, they begin their activity as soon as light intensity exceeds a critical threshold. The variability in time and light level that their activity ceases may be explained by the daily differences in food availability and timing of food satiation. It is unclear whether light is visually limiting to the fish at night or whether their diel patterns are more behavioral such that fish utilize daytime hours because foraging success is greater during the day.
Atka mackerel have adapted to conditions in Seguam Pass and other areas among the Aleutian Islands where current velocities can flow in excess of 4 knots. This study, as well as an ongoing spaghetti tag study (Fritz et al. 2001) which examines the horizontal movements of Atka mackerel, suggests that horizontal migrations are somewhat localized (L. Fritz \& S. McDermott pers. comm.). The archival tag data indicate that fish often underwent relatively quick daytime excursions to more than $50 \mathrm{~m}$ above their nighttime settling depth (Fig. 5). Fish rarely remained this high in the water column for more than $0.5 \mathrm{~h}$. These quick excursions may allow the fish to feed in the water column, yet remain relatively close to a home site without being displaced by strong currents. During periods of greater current velocities (spring tides), Atka mackerel traveled shorter distances toward the surface (Table 1, Fig. 9) and traveled greater distances down a slope (Table 2, Fig. 10). While this might illustrate a tradeoff between feeding success and home-site fidelity, it is possible that Atka mackerel are following the prey source which may also be affected by high current velocities. Fish that underwent dives at depths greater than of $320 \mathrm{~m}$ may have been following a prey source. Quick excursions may also serve to reduce vulnerability to predators such as Steller sea lions, by reducing the time that Atka mackerel spend up in the water column during the day.

Atka mackerel undertake vertical excursions characterized by depth ranges and speeds that may be unique to fishes which lack a swimbladder. Species such as north-east Arctic cod (Gadus morhua L.) that possess a physoclistic swimbladder are capable of relatively quick vertical excursions, but there is an upper limit to their free vertical range (Arnold \& Greer Walker 1992). In some cases, Atka mackerel (Tags 42, 150 and 201) underwent relatively quick vertical migrations from near the bottom to surface waters (Fig. 2). One Atka mackerel (Tag 150), for example, underwent 9 different excursions from below $90 \mathrm{~m}$ to above $20 \mathrm{~m}$ within periods ranging from 7 to $30 \mathrm{~min}$. For fishes with swimbladders (e.g. Gadus morhua L.), quick excursions of this distance that end so close to the surface would likely cause swimbladder damage (Godø \& Michalsen 2000).

\section{Spawning versus nonspawning behavior}

Some differences in vertical movement patterns among fish at different capture locations can be attributed to differences between spawning and nonspawning behavior. The 2 tows, where fish were initially captured, were quite different in terms of sex-ratio and spawning condition. The first tow (Haul 4) was com- 


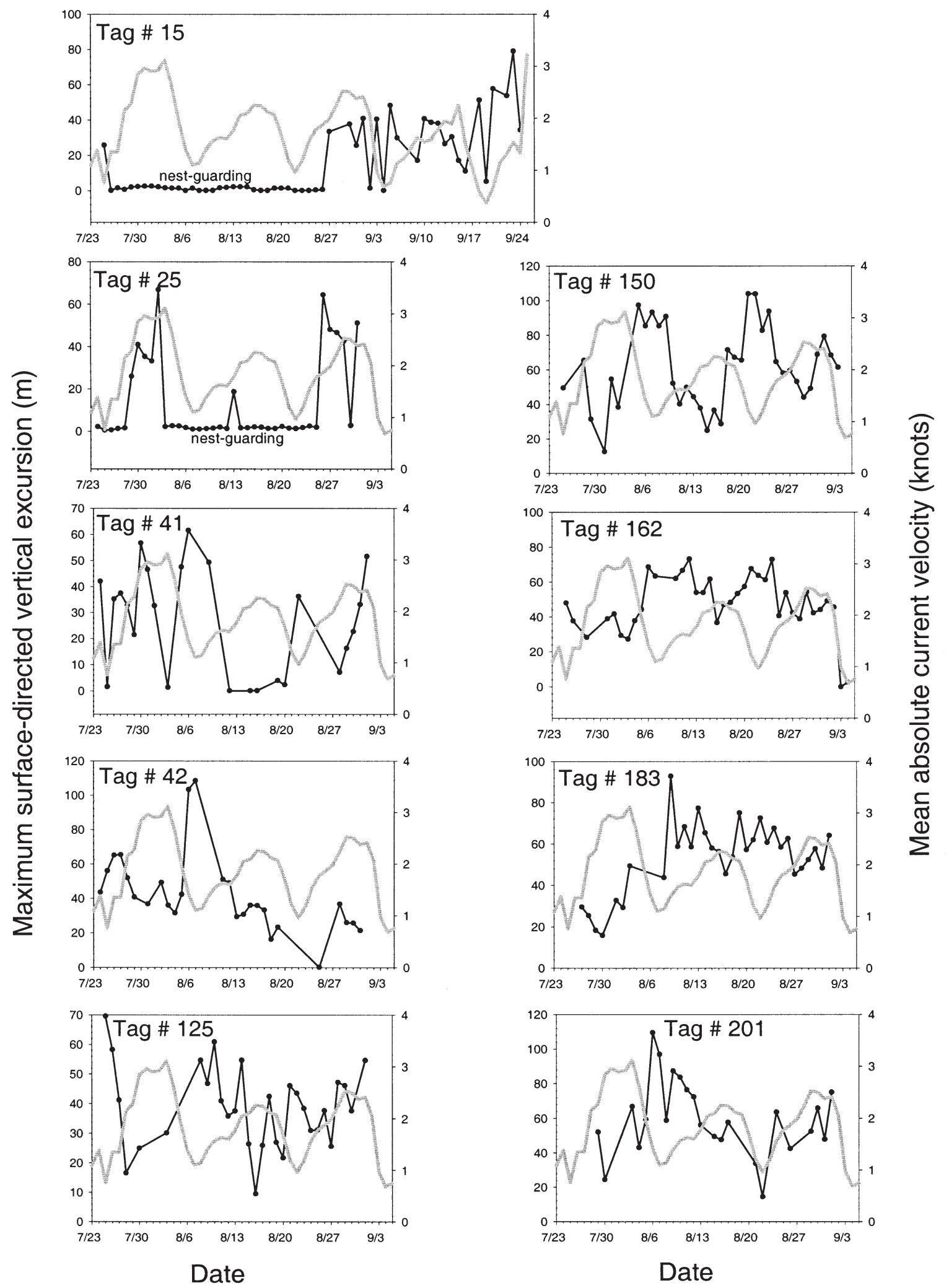

Fig. 9. Pleurogrammus monopterygius. Maximum surface-directed vertical excursion distance (black line) as related to the current velocity (disregarding direction) averaged by day (gray line). Note that current velocity peaks indicate spring tide periods and troughs indicate neap tide periods. Periods of nest-guarding activity are indicated. Only data where light intensity at $150 \mathrm{~m}$ depth was $>2.48 \times 10^{-3} \mu \mathrm{mol}$ photons $\mathrm{m}^{-2} \mathrm{~s}^{-1}$ are included 

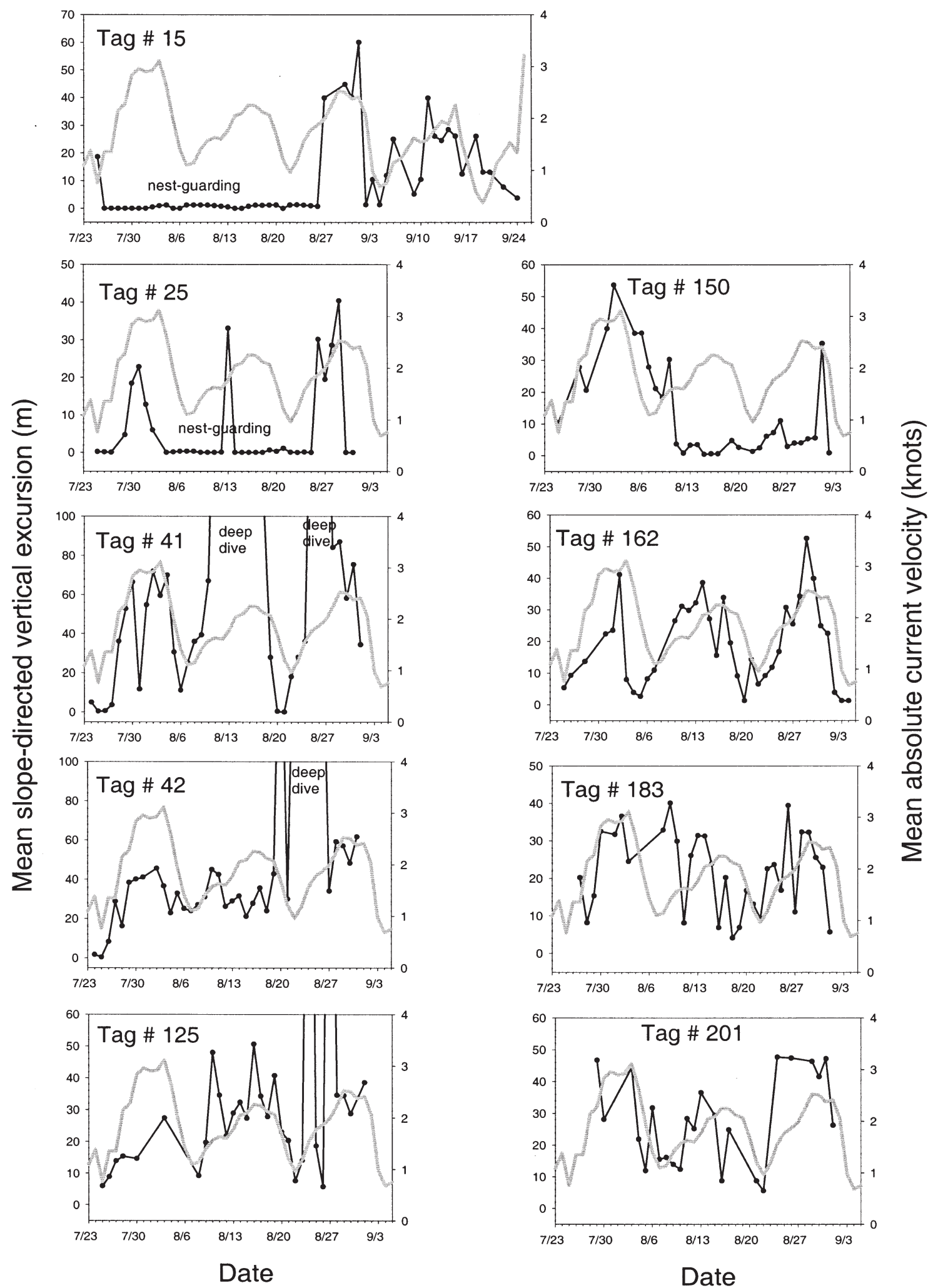

Fig. 10. Pleurogrammus monopterygius. Maximum slope-directed vertical excursion distance (black line) as related to the current velocity (disregarding direction) averaged by day (gray line). Note that current velocity peaks indicate spring tide periods and troughs indicate neap tide periods. Periods of nest-guarding activity and periods during which fish underwent deep-dives beyond the depth limit of the tags $(320 \mathrm{~m})$ are indicated. Only data where light intensity at $150 \mathrm{~m} \mathrm{depth}$ was $>2.48 \times 10^{-3} \mu \mathrm{mol}$ photons $\mathrm{m}^{-2} \mathrm{~s}^{-1}$ are included 


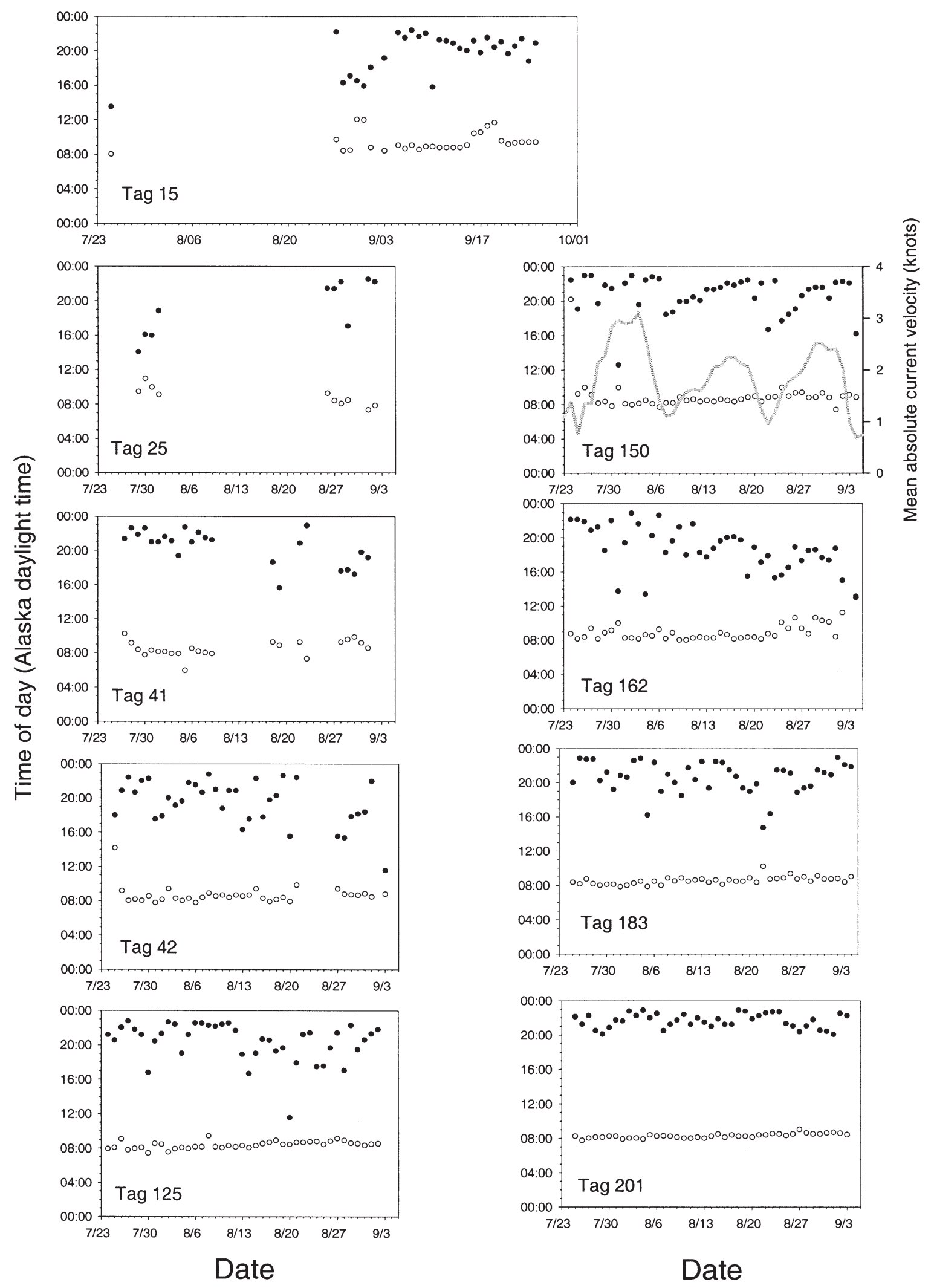

Fig. 11. Pleurogrammus monopterygius. Beginning times ( $($ ) and ending times $(\bullet)$ of Atka mackerel vertical movements within a $24 \mathrm{~h}$ period. Beginning time was defined as the earliest time during each $24 \mathrm{~h}$ day that a fish moved $\geq 1.5 \mathrm{~m}$. Ending time was defined as the last time during the day that a fish moved vertically $\geq 1.5 \mathrm{~m}$ 
prised primarily of bright yellow males, a color indicative of spawning males (Rutenberg 1962, Zolotov 1993). The second (Haul 7), approximately $2.4 \mathrm{~km}$ southeast of the first, was comprised of $37 \%$ males and $63 \%$ females (Fig. 1). Males from this tow, however, were not brightly colored, suggesting a non-spawning condition.

Based on the bright yellow coloration of males from Haul 4, as well as the apparent nest-guarding behavior displayed by 2 of the males captured in this tow, we assume that this location was a spawning site. The 115 to $117 \mathrm{~m}$ bottom depth was unexpected considering that nest-guarding by male Atka mackerel was presumed to occur much closer to shore (Gorbunova 1962, Zolotov 1993, McDermott \& Lowe 1997). Spawning grounds for Atka mackerel off the Kamchatka coast in the western Bering Sea were reported to be at bottom depths of less than $35 \mathrm{~m}$ (Gorbunova 1962, Zolotov 1993). Both fish were tagged and released within $0.5 \mathrm{~km}$ of the initial capture location; therefore, it is reasonable to assume that they returned to their nesting site. Four of the 5 fish from this first tow remained relatively close $(<3 \mathrm{~km})$ to the initial capture and release location. Bottom temperatures during periods of nest-guarding for the 2 nest-guarding males (Tags 15 and 25$)$ averaged $4.55^{\circ} \mathrm{C}(\mathrm{SE}=0.0020, \mathrm{n}=14071)$.

The 4 fish from the second tow were all captured more than $11 \mathrm{~km}$ from the release location. None of these fish displayed nest-guarding activity, nor did they undergo deep dives (Fig. 2). Although not thought to be related to spawning, only fish from the first tow underwent deep excursions beyond the depth limit of the tags $(320 \mathrm{~m})$.

\section{Management implications}

The diel behavior displayed by Atka mackerel indicates that they are less likely to be on the bottom during the day than during the night. Not surprisingly, anecdotal information from commercial fishermen operating in US waters, as well as information from those in the western Bering Sea (Medveditsyna 1962), has suggested that bottom trawling for Atka mackerel is most effective during the night.

Variability in trawl survey abundance estimates for Atka mackerel within the Aleutian Islands region has primarily been attributed to their patchy distribution. The diel vertical behavior of Atka mackerel introduces another source of error, particularly since these surveys have been conducted solely during daylight hours. A potential solution may be to conduct nighttime bottom trawl tows for Atka mackerel, because a greater and less variable proportion of the population would be available to a bottom trawl at night.
Acknowledgements. We greatly appreciate Liz Chilton's help with the tag procedure in Kodiak as well as tagging in Seguam Pass. Lowell Fritz, Rebbeca Reuter and Scott McKillip were equally helpful during the tagging process. Jerry Hoff, Rebecca Reuter and Erika Acuna deserve thanks for their efforts during the tag recovery cruise. We thank the skippers, crew and observers aboard the FVs 'Alaska Ranger', 'Alaska Spirit', 'Alaska Warrior', 'Ocean Peace', 'Seafreeze' and 'Seafisher' for their cooperation and participation in the tag recovery process. Troy Martin and Sheryl Corey helped distribute tag reward posters. Holly Moore of ADF\&G provided supplies needed for deploying the light/current meter. Ken Doris of Westward Seafoods donated the crab pots for the light/current meters. We thank Taina Honkalehto, Mike Guttormsen, Kevin Landgraf and Bill Floering for their efforts capturing Atka mackerel specimens for use in Kodiak. Kathryn Chumbley supplied frozen Atka mackerel which helped formulate the tagging procedure. Rich Titgen and Al Stoner post-calibrated the light sensor. We thank Roger Dennison of Conservation Devices Inc. for designing a data storage tag that was effective for smaller fish and Trey Walker for his advice on use of the tags. Lowell Fritz, Kevin Bailey, Steve Syrjala and Gary Walters reviewed early versions of this manuscript.

\section{LITERATURE CITED}

Arnold GP, Greer Walker M (1992). Vertical movements of cod (Gadus morhua L.) in the open sea and the hydrostatic function of the swimbladder. ICES J Mar Sci 49:357-372

Cobb JN (1907) Report on the fisheries of Alaska. In: The fisheries of Alaska in 1906. US Bureau of Fisheries. Document no. 618, Washington

Fritz LW, Lowe SA (1998) Seasonal distributions of Atka mackerel (Pleurogrammus monopterygius) in commercially-fished areas of the Aleutian Islands and Gulf of Alaska. NOAA Technical Memo NMFS-AFSC-92. US Department of Commerce, Seattle, WA

Fritz LW, McDermott SF, Lowe SA (2001) Efficacy of trawl fishery exclusion zones in maintaining prey availability for Steller sea lions: description of Atka mackerel tagging project in Seguam Pass, Aleutian Islands, AK, in 1999 and 2000. In: Fadely BS (ed) Steller sea lion investigations, 2000. AFSC Proc Rep 2001-05. Alaska Fisheries Science Center, Natl Mar Fish Ser, NOAA, Seattle

Godø OR, Michalsen K (2000) Migratory behavior of northeast Arctic cod, studied by use of data storage tags. Fish Res 48:127-140

Gorbunova NN (1962) Spawning and development of greenlings (family Hexagrammidae). In: Rass TS (ed) Greenlings: taxonomy, biology, interoceanic transplantation. (Translated from Russian by Isr Prog Sci Trans, 1970.) TT 69:55097. Available from US Dep Commerce, Clearinghouse for Fed Sci and Tech Inf, Springfield, VA, p 121-185

Lowe SA, Fritz LW (2000) Atka mackerel. In: Stock assessment and fishery evaluation report for the groundfish resources of the Bering Sea/Aleutian Islands Region as projected for 2000. North Pacific Fisheries Management Council, Anchorage, AK

McDermott SF, Lowe SA (1997) The reproductive cycle and sexual maturity of Atka mackerel, Pleurogrammus monopterygius, in Alaska waters. Fish Bull 95:321-333

Medveditsyna AV (1962) Data on the Atka mackerel (Pleurogrammus monopterygius [Pallas]). In: Rass TS (ed) Greenlings: taxonomy, biology, interoceanic transplantation. (Translated from Russian by Isr Prog Sci Trans, 1970.) TT 69: 
55097. Available from US Dep Commerce, Clearinghouse for Fed Sci and Tech Inf, Springfield, VA, p 104-106

Merrick RL, Chumbley MK, Byrd GV (1997) Diet diversity of Steller sea lions (Eumetopias jubatus) and their population decline in Alaska: a potential relationship. Can J Fish Aquat Sci 54:1342-1348

Orlov AM (1997) On the feeding of Atka mackerel Pleurogrammus monopterygius in the Pacific waters of the northern Kuril Islands. J Ichthyol 37(3):226-231

Rutenberg EP (1962) Survey of the fishes of family Hexagrammidae. In: Rass TS (ed) Greenlings: taxonomy, biology, interoceanic transplantation. (Translated from Russian by Isr. Prog. Sci. Trans., 1970.) TT 69:55097. Available from US Dep Commerce, Clearinghouse for Fed Sci and Tech Inf, Springfield, VA, p 1-103

Editorial responsibility: Otto Kinne (Editor), Oldendorf/Luhe, Germany
Sinclair EH, Zeppelin TK (2002) Seasonal and spatial differences in diet in the western stock of Steller sea lions (Eumetopias jubatus). J Mammal 83 (in press)

S-PLUS (2000) S-PLUS 2000 User's guide. Data analysis products division, MathSoft, Seattle, WA

Yang M (1999) The trophic role of Atka mackerel, Pleurogrammus monopterygius, in the Aleutian Islands area. Fish Bull 97:1047-1057

Zar JH (1984) Biostatistical analysis. Prentice-Hall, New York

Zolotov OG (1981) On sexual dimorphism in the Atka mackerel, Pleurogrammus monopterygius. J Ichthyol 21(2):49-54

Zolotov OG (1993) Notes on the reproductive biology of Pleurogrammus monopterygius in Kamchatkan waters. J Ichthyol 33(4):25-37

Submitted: December 6, 2001; Accepted: April 25, 2002 Proofs received from author(s): August 9, 2002 